University of Nebraska - Lincoln

DigitalCommons@University of Nebraska - Lincoln

U.S. Environmental Protection Agency Papers

U.S. Environmental Protection Agency

2008

\title{
Perfluorinated compounds in whole fish homogenates from the Ohio, Missouri, and Upper Mississippi Rivers, USA
}

Xibiao Ye

U.S. Environmental Protection Agency

Mark J. Strynar

U.S. Environmental Protection Agency

Shoji F. Nakayama

U.S. Environmental Protection Agency

Jerry Varns

U.S. Environmental Protection Agency

Larry Helfant

U.S. Environmental Protection Agency

See next page for additional authors

Follow this and additional works at: https://digitalcommons.unl.edu/usepapapers

Ye, Xibiao; Strynar, Mark J.; Nakayama, Shoji F.; Varns, Jerry; Helfant, Larry; Lazorchak, James; and Lindstrom, Andrew B., "Perfluorinated compounds in whole fish homogenates from the Ohio, Missouri, and Upper Mississippi Rivers, USA" (2008). U.S. Environmental Protection Agency Papers. 112.

https://digitalcommons.unl.edu/usepapapers/112

This Article is brought to you for free and open access by the U.S. Environmental Protection Agency at DigitalCommons@University of Nebraska - Lincoln. It has been accepted for inclusion in U.S. Environmental Protection Agency Papers by an authorized administrator of DigitalCommons@University of Nebraska - Lincoln. 


\section{Authors}

Xibiao Ye, Mark J. Strynar, Shoji F. Nakayama, Jerry Varns, Larry Helfant, James Lazorchak, and Andrew B. Lindstrom 


\title{
Perfluorinated compounds in whole fish homogenates from the Ohio, Missouri, and Upper Mississippi Rivers, USA
}

\author{
Xibiao Ye ${ }^{a}$, Mark J. Strynar ${ }^{a}$, Shoji F. Nakayama ${ }^{\text {, }}$ Jerry Varns ${ }^{\text {, }}$, Larry Helfant ${ }^{\text {, }}$ \\ James Lazorchak ${ }^{\mathrm{b}}$, Andrew B. Lindstrom ${ }^{\mathrm{a}, *}$ \\ ${ }^{a}$ Human Exposure and Atmospheric Sciences Division, National Exposure Research Laboratory, US Environmental Protection Agency, Research Triangle Park, NC 27711, USA \\ ${ }^{\mathrm{b}}$ Ecological Exposure Research Division, National Exposure Research Laboratory, MD E205-04, US Environmental Protection Agency, Cincinnati, OH 45268, USA
}

Perfluorinated compounds were measured in whole fish homogenates collected from the Ohio, Missouri, and upper Mississippi Rivers in the east central US.

\section{A R T I C L E I N F O}

\section{Article history:}

Received 14 January 2008

Received in revised form 13 March 2008

Accepted 21 March 2008

\section{Keywords:}

Perfluorinated organic compounds (PFCs)

Perfluorooctanoic acid (PFOA)

Perfluorooctane sulfonate (PFOS)

Fish

Method validation

\begin{abstract}
A B S T R A C T
A method for the analysis of 10 perfluorinated compounds (PFCs) in whole fish homogenate is presented and applied to 60 fish samples collected from the Ohio, Missouri, and upper Mississippi Rivers in 2005. Method accuracy ranged between 86 and 125\% with limits of quantitation between 0.2 and $10 \mathrm{ng} / \mathrm{g}$ wet weight. Intra- and inter-batch precision was generally $\pm 20 \%$. Perfluorooctane sulfonate (PFOS) was the predominant compound identified in these samples, contributing over $80 \%$ of total PFC composition in the fish from these rivers, with median PFOS concentrations of $24.4,31.8$, and $53.9 \mathrm{ng} / \mathrm{g}$ wet wt in the Missouri, Ohio, and Mississippi Rivers, respectively. Median PFOS levels were significantly $(p=0.01)$ elevated in piscivorous fish $(88.0 \mathrm{ng} / \mathrm{g})$ when compared with non-piscivorous fish $(15.9 \mathrm{ng} / \mathrm{g})$. The 10 samples with PFOS concentrations above $200 \mathrm{ng} / \mathrm{g}$ were broadly scattered across all three rivers, providing evidence of the widespread presence of this compound in these US waterways.
\end{abstract}

Published by Elsevier Ltd.

\section{Introduction}

Perfluorinated compounds (PFCs) share a number of unique physical and chemical properties that have made them especially useful for a large number of applications, including polymers, paints, water repellents, lubricants, paper coatings, cosmetics, and fire-fighting foams (Prevedouros et al., 2006). While these compounds have been used worldwide for more than 50 years, it has only recently become apparent that perfluorooctane sulfonate (PFOS) and perfluorooctanoic acid (PFOA) are persistent, bioaccumulative, and toxic (Kudo and Kawashima, 2003; Seacat et al., 2003; Kennedy et al., 2004), raising concern about their presence in the environment and potential human exposure.

Preliminary risk assessments conducted for PFOS by the Organisation for Economic Co-operation and Development (2002) and for PFOA by the US Environmental Protection Agency (US EPA) (2002), indicate that these compounds may adversely affect wildlife and human health. Regulations and agreements limiting the production and emission of many PFCs have already been established (US EPA, 2006a), and guidelines for their presence in

\footnotetext{
* Corresponding author. Tel.: +1 919541 0551; fax: +1 9195413527

E-mail address: lindstrom.andrew@epa.gov (A.B. Lindstrom).
}

drinking and surface water have been issued by authorities in some locations (Minnesota Department of Health, 2007a; State of New Jersey Department of Environmental Protection, 2007).

While a wide range of PFCs have been detected in various environmental and biological matrices, little is known about the distribution and accumulation of these materials in the environment. A limited number of studies have documented the presence of PFCs in fresh water (Hansen et al., 2002; Boulanger et al., 2004; Nakayama et al., 2007) and oceanic samples (Yamashita et al., 2005) and in fish in some locations around the world (Houde et al., 2006), but in general, literature on their distribution remains very sparse.

The majority of the work concerning PFCs in fresh water fish has been based on the analysis of blood or liver samples, which is where the PFCs have been found to concentrate (Giesy and Kannan, 2001; Houde et al., 2006). Although whole fish homogenates have been frequently used in ecological risk assessments involving persistent organic pollutants (Weisbrod et al., 2007), only a small number of studies, centered in the US Great Lakes Region, have used this approach to evaluate the distribution of the PFCs in fish (Martin et al., 2004; Furdui et al., 2007).

At present, limited information is available regarding the performance characteristics of analytical methods for quantifying PFCs in fish tissue. In general, studies have been hampered by analytical challenges such as low PFC concentrations, poor recoveries, lack of 
high quality analytical standards, use of external solvent-based calibration curves, and the unusual physical-chemical properties of perfluoroalkyl chemicals (van Leeuwen et al., 2006). Moreover, most of the work to date has been based on an ion-pair extraction method (Hansen et al., 2001) that may underestimate the actual concentration of many PFCs in unknown samples, most likely due to various matrix effects which inhibit ionization during mass spectrometry (van Leeuwen et al., 2006).

In a recent inter-laboratory study evaluating these methodological shortcomings, agreement between the participating laboratories was shown to be poor for more complex and variable matrices such as fish muscle tissue, fish liver, and water (van Leeuwen et al., 2006). The low percentages of satisfactory PFOS results for fish tissue (17\%) and fish liver (55\%) suggest that improved extraction and cleanup procedures are needed to better characterize the concentrations of these compounds in fish. In an effort to provide more accurate and effective methods, Taniyasu et al. (2005) have compared the extraction efficiency of the conventional ion-pair method with an alkaline digestion/solid phase extraction (AD/SPE) method using human blood and beaver liver samples as test matrices. They found that compared to the conventional approach, the $\mathrm{AD} / \mathrm{SPE}$ method led to a 3-5 fold increase in PFOS and other PFC concentrations recovered from the beaver liver samples, indicating substantially greater recoveries and more realistic estimates of the actual values. In this study, we apply a modification of this approach to whole fish homogenate samples in an effort to further characterize its performance and potential utility in dealing with this challenging matrix.

The USEPA has been conducting probabilistic monitoring research under the Environmental Monitoring and Assessment Program (EMAP) (US EPA, 2006b). In 2004-2006, EMAP conducted a probabilistic survey of three great rivers, the Ohio, Missouri, and upper Mississippi Rivers (EMAP GRE), to develop and demonstrate tools to assess the ecological conditions in these important freshwater resources. Fish samples were collected and whole body homogenates were prepared as part of this effort to provide material that could be used to evaluate the bioaccumulation of persistent toxic substances. These samples were also intended to estimate regional and river-wide scales of exposure to contaminants associated with fish consumption for higher trophic levels. Although whole-fish contamination is primarily an indicator of risk to piscivorous wildlife, whole-fish data may also be relevant for estimating human exposure to contaminants through fish consumption.

The objectives of this study were to refine an AD/SPE-based PFC measurement technique for use with whole fish homogenates and to test this method on a subset of samples collected during the 2005 EMAP GRE sampling season along the Ohio, Missouri, and upper Mississippi Rivers. The intent of this work was to validate this method and to provide data on the distribution of PFCs in fish collected from these great river systems.

\section{Materials and methods}

\subsection{Reagents}

Standards of perfluorobutane sulfonate (PFBS), perfluorohexane sulfonate (PFHxS), and perfluorooctane sulfonate (PFOS) were provided by $3 \mathrm{M}$ Corporation (Saint Paul, MN). Perfluorohexanoic acid (PFHxA), perfluoroheptanoic acid (PFHpA), perfluorooctanoic acid (PFOA), perfluorononanoic acid (PFNA), perfluorodecanoic acid (PFDA), perfluroundecanoic acid (PFUnA), and perfluorododecanoic acid (PFDoA) were purchased from Oakwood Products (West Columbia, SC). Stable isotopically labeled internal standards, $\left[{ }^{18} \mathrm{O}_{2}\right]$ ammonium perfluorooctane sulfonate and $\left[1,2-{ }^{13} \mathrm{C}_{2}\right]$ perfluorooctanoic acid, were obtained from Research Triangle Institute (Research Triangle Park, NC) and Perkin Elmer Life and Analytical Sciences (Boston, MA), respectively. The purity of all the analytical standards exceeded $90 \%$. Methanol was purchased from Burdick \& Jackson (Muskegon, MI). Sodium hydroxide, sodium acetate, glacial acetic acid, ammonium acetate and ammonium hydroxide were obtained from Sigma-Aldrich Chemical (St Louis, MO). A listing of the target compounds, acronyms, and related information appears in the Supporting information (Table S1).

\subsection{Fish collection}

Fish were collected from 30 different sites on the Ohio, Missouri, and Upper Mississippi Rivers (10 sites for each river, Fig. 1) as part of the US EPA's EMAP-GRE program in 2005 (US EPA, 2006b). The 10 sites were selected from each of the three rivers in order to provide equidistant coverage over the entire sample area. Collectively, these sites represent 5120 river kilometers in a 12 state region of the east central United States. Samples were obtained by daytime electrofishing along two $500 \mathrm{~m}$ shoreline transects per site. Fish were composited by species, wrapped in foil, and placed in a double plastic bag on ice (US EPA, 2006b). At every sample site, two composite fish samples were collected: a small-fish sample ( $<120 \mathrm{~mm}$ for minnows, dace and shiners; $<150 \mathrm{~mm}$ for gizzard shad) and a large-fish sample ( $>120 \mathrm{~mm}$ ). The small-fish sample was a composite of 20-200 individuals of one species whose adults are small. The large-fish sample included 3-5 individuals of one species whose adults were larger. A listing of the species collected and the designations used in the following analyses appears in Supporting information (Table S2). Each sample was assumed to accurately represent the proportional abundance of the littoral fish assemblage at that site. After transport to the laboratory, the fish composites were frozen at $-20^{\circ} \mathrm{C}$ until further processing was completed.

\subsection{Preparation of whole fish homogenates}

After thawing the samples at $4{ }^{\circ} \mathrm{C}$, bigger fish ( $>100 \mathrm{~g}$ ) were cut into chunks with a knife, put through a Hobart Food Cutter 84145 (Hobart, Troy, OH), and then homogenized in a Waring Model 701HS Blender (Waring Products, Torrington, CT). Smaller fish were chopped with a knife and then further homogenized in the blender. The homogenates were put into polyethylene containers and refrozen at $-20^{\circ} \mathrm{C}$. A subsample of these homogenates was sent to the analytical lab where it was thawed, weighed, diluted $1: 1$ with water $(1.0 \mathrm{~mL}$ water per gram fish), and rehomogenized with a Polytron homogenizer (Brinkmann Instruments, Westbury, $\mathrm{NY}$ ). A $1.0 \mathrm{~mL}$ subsample of this homogenate (containing $0.5 \mathrm{~g}$ of fish) was placed in a $15 \mathrm{~mL}$ polypropylene tube containing $9.0 \mathrm{~mL}$ of $10 \mathrm{mM}$ sodium hydroxide/methanol solution and allowed to digest on an orbital shaker for $16 \mathrm{~h}$ at room temperature. After digestion, samples were centrifuged at $2000 \times \mathrm{g}$ for $5 \mathrm{~min}$ using an IEC Centra CL12 centrifuge (Thermo Fisher Scientific Inc., Waltham, MA), and then $1.0 \mathrm{~mL}$ of the supernatant was added to $9.0 \mathrm{~mL}$ of deionized water prior to SPE cleanup. Oasis WAX 3cc SPE cartridges (Waters Corporation, Milford, MA) were preconditioned with $4.0 \mathrm{~mL}$ of $0.1 \%$ ammonium hydroxide in methanol followed by $4.0 \mathrm{~mL}$ of methanol and $4.0 \mathrm{~mL}$ of deionized water. Ten milliliters of the diluted digest supernatant was then loaded onto the cartridge and washed with $4.0 \mathrm{~mL}$ of $25 \mathrm{mM}$ sodium acetate buffer $(\mathrm{pH} 4)$ followed by $4.0 \mathrm{~mL}$ of methanol. The target compounds were eluted with $4.0 \mathrm{~mL}$ of $0.1 \%$ ammonium hydroxide in methanol. This final eluate was concentrated to $0.5 \mathrm{~mL}$ under nitrogen gas using a Turbo-Vap LV evaporator (Caliper Life Sciences, Hopkinton, MA). Samples were prepared by combining $280 \mu \mathrm{L}$ of the final eluate with $120 \mu \mathrm{L}$ of $2 \mathrm{mM}$ ammonium acetate buffer in autosampler vials.

\subsection{HPLC/MS/MS analysis}

PFC analysis was performed using a high-performance liquid chromatographytandem mass spectrometry (HPLC/MS/MS) system consisting of an Agilent 1100 liquid chromatograph (Agilent Technologies, Palo Alto, CA) interfaced with a PE Sciex API 3000 triple quadrupole mass spectrometer (Applied Biosystems/MDS Sciex, Foster City, CA). A $10 \mu \mathrm{L}$ aliquot of sample extract was injected and separation was achieved using a Luna C18 (2) $3 \times 50 \mathrm{~mm}$ column $(5 \mu \mathrm{m}$, fitted with a C18 guard column, Phenomenex, Torrance, CA) using an isocratic mobile phase of $30 \% 2 \mathrm{mM}$ ammonium acetate and $70 \%$ methanol at a flow rate of $200 \mu \mathrm{L} / \mathrm{min}$. The MS/MS was operated in multiple reaction monitoring (MRM) mode using the mass transitions listed in Table S1. All concentrations discussed below are presented as ng of PFC/g wet weight of fish.

\subsection{Quality assurance and control}

Double blanks (containing only mobile phase) were injected prior to running each batch and once every five samples to monitor for potential PFC contamination from the instrument. Method blanks (containing only deionized water) and matrix blanks (containing blank fish matrix) were treated the same as actual samples in order to monitor potential contamination during sample preparation. Matrix blanks were derived from whole body homogenates of ornamental Koi (Cyprinus carpio) from Carolina Biological Supply Company (Burlington, NC). This material was found to have only negligible levels of the target PFCs and was used for the construction of matrix spiked calibration curves and quality control (QC) pools.

Calibration standards and QC pools were prepared by spiking PFC standards directly into Koi homogenate at levels intended to represent the concentrations anticipated in the unknown samples. Pilot tests indicated that PFOS concentrations were 1-3 orders of magnitude higher than the concentrations of the other PFC compounds of interest; therefore, the calibration range for PFOS was 


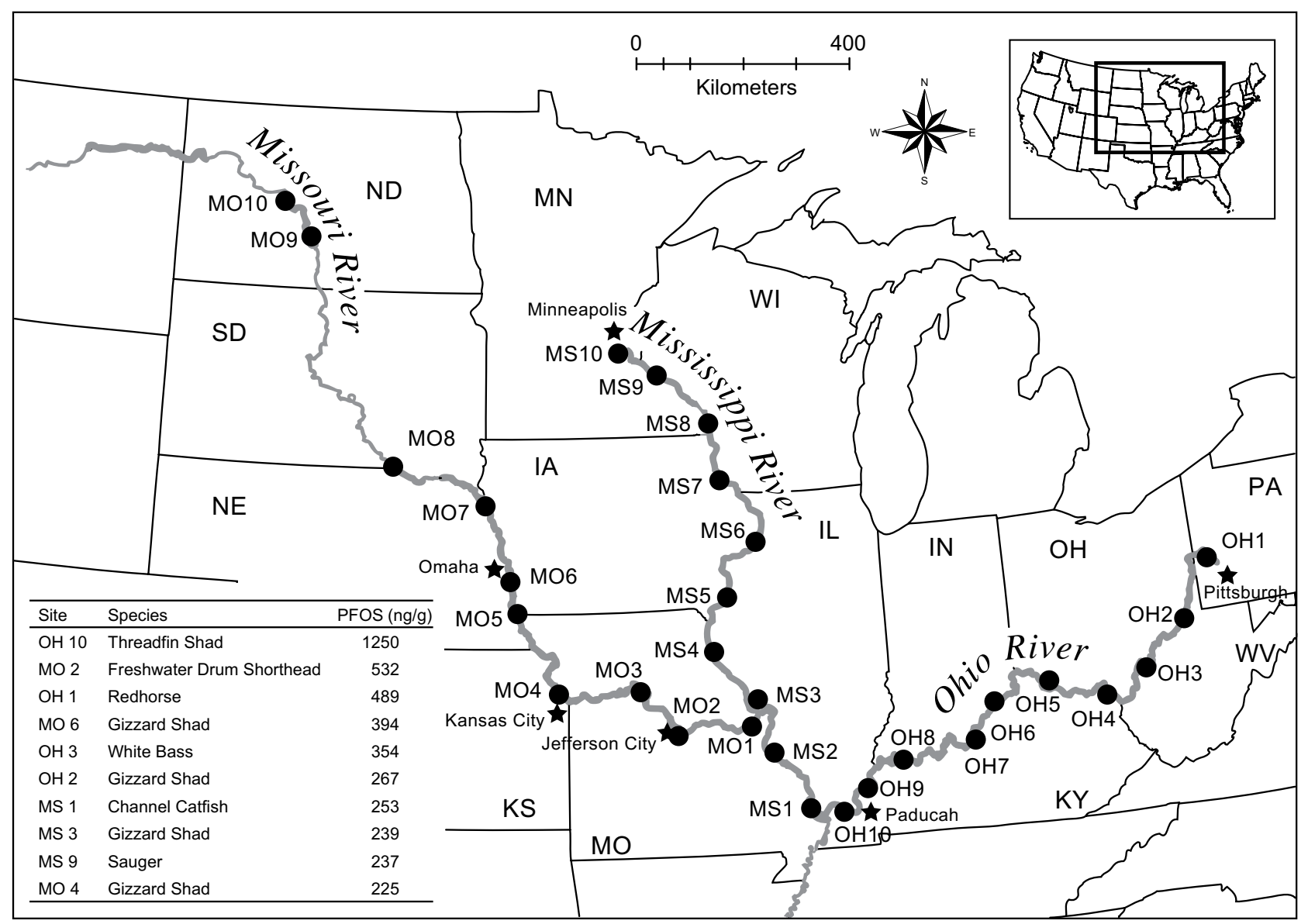

Fig. 1. Sampling sites along the Ohio (OH), Missouri (MO), and Mississippi (MS) Rivers. The accompanying list indicates the species and location of samples with PFOS concentrations higher than $200 \mathrm{ng} / \mathrm{g}$.

correspondingly increased. Calibration curves ranging from 10 to $600 \mathrm{ng} / \mathrm{g}$ were prepared daily for PFOS. After the initial analysis, five of the 60 samples had PFOS concentrations greater than $600 \mathrm{ng} / \mathrm{g}$, therefore it was necessary to prepare a new overlapping calibration curve ranging from 200 to $4000 \mathrm{ng} / \mathrm{g}$. For the other nine target PFCs, calibration curves were prepared from 0.2 to $100 \mathrm{ng} / \mathrm{g}$. Separate curves were prepared for PFOS and the other PFCs for each analytical batch. Isotopically labeled PFOA $\left({ }^{13} \mathrm{C}_{2}\right.$-PFOA) and PFOS $\left({ }^{18} \mathrm{O}_{2}\right.$-PFOS $)(5 \mathrm{ng}$ of each) were used as internal standards for the perfluorinated carboxylates and perfluorinated sulfonates, respectively, being added to the fish homogenates before digestion to minimize analytical bias. Quantitation of samples was performed based on the relative response (peak area ratio) of each analyte to the internal standard using calibration curves as described above, adjusting for the known purity of the standards.

QC pools were prepared at $1 \mathrm{ng} / \mathrm{g}$ (low), $20 \mathrm{ng} / \mathrm{g}$ (medium) and $100 \mathrm{ng} / \mathrm{g}$ (high) levels. Separate PFOS QC pools were prepared at $25 \mathrm{ng} / \mathrm{g}$ (low), $100 \mathrm{ng} / \mathrm{g}$ (medium) and $500 \mathrm{ng} / \mathrm{g}$ (high) levels. Multiple QC samples of each concentration were run with the unknown samples so that they represented at least $10 \%$ of the samples run in every analytical batch. Determination of inter- and intra-batch precision was based upon these QC data. The limit of quantitation (LOQ) was set as the lowest point on the calibration curve having an accuracy of $100 \pm 30 \%$, with accuracy being determined by comparing nominal concentrations of low level standards with their predicted concentrations using the standard curve.

\subsection{Statistical analysis}

The mean, median, and range were determined for each compound in each river To allow inclusion of all samples in the statistical analyses, concentrations below the LOQ were assigned a value of one-half of the LOQ. Total PFC concentrations (summation of all concentrations measured) and the percent contribution of each compound to the total were calculated. A nonparametric analysis option in SPSS 13.0 software (SPSS Inc., Chicago, IL) using the Kruskal-Wallis and Mann-Whitney $U$ tests was used with the significance set at the 0.05 level to compare PFC concentrations between various subgroups of samples.

\section{Results}

\subsection{Method performance characteristics}

The LOQ recovery, and precision for each of the target compounds are presented in Table 1. Mean accuracy for all analytes ranged from 86 to $125 \%$ at three different concentration levels. The LOQs ranged from $0.2-1.0 \mathrm{ng} / \mathrm{g}$ for all compounds except PFUnA (0.4-1.0 ng/g), PFBS (0.2-4.0 ng/g), PFHpA (0.2-4.0 ng/g), PFHxA $(2-10 \mathrm{ng} / \mathrm{g})$, and PFOS $(10 \mathrm{ng} / \mathrm{g})$. Intra-batch precision was $<20 \%$ (coefficient of variation, CV) for all analytes except PFHpA (21.6\%) and PFHxA (51.2\%) at the lowest level ( $1 \mathrm{ng} / \mathrm{g}$ ). Inter-batch precision was $<30 \%$ (CV) for all compounds except PFDoA (40.1\%), PFUnA (39.5\%), and PFHxA (42.2\%) at the $1 \mathrm{ng} / \mathrm{g}$ level. All blank samples (containing either blank mobile phase, deionized water, or blank fish matrix) consistently gave results $<$ LOQ for each compound.

\subsection{PFC concentrations in fish}

Table 2 is a summary of the PFC concentrations found in the fish samples from each river in this study. One or more PFC was detected in all the samples except one (sample MO 10b), which was collected in the upper reaches of the Missouri River (Fig. 1). Out of 600 assays (60 fish samples $\times 10$ PFCs), 279 (47\%) were above the LOQ; 87 (44\%) for the Missouri River, 92 (46\%) for the Mississippi River, and 100 (50\%) for the Ohio River. The least frequently detected compounds were PFBS (3/60 samples) and PFOA (6/60 samples), while the most frequently detected was PFOS (49/60 
Table 1

Method performance characteristics of standard-spiked matrix

\begin{tabular}{|c|c|c|c|c|c|c|c|c|c|c|c|c|}
\hline \multirow[t]{2}{*}{ Analytes } & \multirow[t]{2}{*}{$\begin{array}{l}\text { LOQ } \\
(\mathrm{ng} / \mathrm{g})\end{array}$} & \multirow[t]{2}{*}{$\begin{array}{l}\text { Validated } \\
\text { range (ng/g) }\end{array}$} & \multirow[t]{2}{*}{$\begin{array}{l}\text { Correlation } \\
\text { coefficient }(R)\end{array}$} & \multicolumn{3}{|c|}{ Accuracy (\%), mean \pm SD } & \multicolumn{3}{|c|}{$\begin{array}{l}\text { Average intra-assay precision } \\
(\mathrm{CV} \%)\end{array}$} & \multicolumn{3}{|c|}{$\begin{array}{l}\text { Average inter-assay precision } \\
(\mathrm{CV} \%)\end{array}$} \\
\hline & & & & $\begin{array}{l}1 \mathrm{ng} / \mathrm{g} \\
(n=5)\end{array}$ & $\begin{array}{l}20 \mathrm{ng} / \mathrm{g} \\
(n=5)\end{array}$ & $\begin{array}{l}100 \mathrm{ng} / \mathrm{g} \\
(n=7)\end{array}$ & $\begin{array}{l}1 \mathrm{ng} / \mathrm{g} \\
(n=5)\end{array}$ & $\begin{array}{l}20 \mathrm{ng} / \mathrm{g} \\
(n=5)\end{array}$ & $\begin{array}{l}100 \mathrm{ng} / \mathrm{g} \\
(n=7)\end{array}$ & $\begin{array}{l}1 \mathrm{ng} / \mathrm{g} \\
(n=5)\end{array}$ & $\begin{array}{l}20 \mathrm{ng} / \mathrm{g} \\
(n=5)\end{array}$ & $\begin{array}{l}100 \mathrm{ng} / \mathrm{g} \\
(n=7)\end{array}$ \\
\hline$\overline{\text { PFOS }^{\mathrm{a}}}$ & 10.0 & $10-4000$ & 0.98 & $92.4 \pm 12$ & $86.8 \pm 3.4$ & $105 \pm 6.3$ & 5.7 & 3.1 & 3.2 & 13.7 & 2.8 & 6.6 \\
\hline PFHxS & 0.2 & $0.2-100$ & 0.99 & $105 \pm 15$ & $109.2 \pm 8.4$ & $92.2 \pm 4.9$ & 12.7 & 9.7 & 3.5 & 13.2 & 2.9 & 4.8 \\
\hline PFBS & $0.2-0.4$ & $0.2-100$ & 0.97 & $103 \pm 15$ & $111 \pm 5.9$ & $98.3 \pm 14$ & 14.1 & 5.3 & 5.3 & 4.7 & 4.4 & 16.4 \\
\hline PFDoA & $0.2-1.0$ & $0.2-100$ & 0.99 & $103 \pm 33$ & $106 \pm 19$ & $105 \pm 22$ & 15.8 & 15.1 & 13.8 & 40.1 & 11.7 & 17.9 \\
\hline PFUnA & $0.4-1.0$ & $0.4-100$ & 0.98 & $111 \pm 29$ & $105 \pm 22$ & $107 \pm 21$ & 14.4 & 18.8 & 12.0 & 39.5 & 8.8 & 17.3 \\
\hline PFDA & $0.2-1.0$ & $0.2-100$ & 0.99 & $104 \pm 27$ & $100 \pm 13$ & $109 \pm 23$ & 18.4 & 13.8 & 13.0 & 28.8 & 4.4 & 21.2 \\
\hline PFNA & 0.2 & $0.2-100$ & 0.99 & $98.7 \pm 12$ & $99.6 \pm 7.2$ & $111 \pm 25$ & 2.1 & 7.1 & 10.7 & 16.2 & 6.0 & 25.2 \\
\hline PFOA & $0.2-1.0$ & $0.2-100$ & 0.99 & $85.8 \pm 7.9$ & $102 \pm 5.1$ & $113 \pm 25$ & 2.1 & 1.9 & 8.9 & 9.0 & 5.9 & 24.6 \\
\hline PFHрA & $0.2-4.0$ & $0.2-100$ & 0.98 & $100 \pm 24$ & $102 \pm 7.7$ & $114 \pm 24$ & 21.6 & 5.7 & 8.7 & 19.3 & 7.6 & 23.7 \\
\hline PFHxA & $2.0-10.0$ & $2.0-100$ & 0.94 & $111 \pm 40$ & $105 \pm 19$ & $125 \pm 29$ & 51.2 & 1.3 & 6.8 & 42.2 & 9.9 & 26.9 \\
\hline
\end{tabular}

$\mathrm{SD}$, standard deviation.

a PFOS spiked levels: low 25 ng/g, medium $100 \mathrm{ng} / \mathrm{g}$, and high $500 \mathrm{ng} / \mathrm{g}$.

samples) with an overall median concentration of $37.4 \mathrm{ng} / \mathrm{g}$. The median PFOS level in the Mississippi River $(53.9 \mathrm{ng} / \mathrm{g}$ ) was higher than the Ohio River (31.8 ng/g) and Missouri River (24.4 ng/g), although the differences were not statistically significant. The highest concentration of PFOS, $1250 \mathrm{ng} / \mathrm{g}$, was found in threadfin shad (Dorosoma petenense) from the Ohio River (sample site $\mathrm{OH} 10 \mathrm{a}$ ). Fig. 1 indicates that elevated PFOS concentrations were broadly distributed in this survey, with 10 sites (17\%) having samples above $200 \mathrm{ng} / \mathrm{g}$ (four samples on the Ohio River, three on the Mississippi River, and three on the Missouri River).

The other PFCs were all generally at least an order of magnitude lower than PFOS, with an overall median concentration for PFHxA at $3.71 \mathrm{ng} / \mathrm{g}$, PFDA at $0.82 \mathrm{ng} / \mathrm{g}$, and PFHxS at $0.36 \mathrm{ng} / \mathrm{g}$. Notably high values of the other PFCs were also broadly dispersed among the rivers, including PFHxS at $8.14 \mathrm{ng} / \mathrm{g}$ on the Missouri River (sample MO 6b), PFUnA at $48.0 \mathrm{ng} / \mathrm{g}$ on the Mississippi River (sample MS 1a), and PFDA at $9.01 \mathrm{ng} / \mathrm{g}$ (samples $\mathrm{OH} 4 \mathrm{a}$ and $\mathrm{OH} 5 \mathrm{a}$ ), and PFHxA at $18.4 \mathrm{ng} / \mathrm{g}$ (sample $\mathrm{OH} 4 \mathrm{~b}$ ), both on the Ohio River. It is also interesting to note that the median levels of PFDoA $(1.87 \mathrm{ng} / \mathrm{g})$, PFUnA (4.52 ng/g), and PFDA (4.10 ng/g) in fish from the Ohio River were all significantly higher than those in the Mississippi and Missouri Rivers $(p<0.05)$. The current study is the first we found which determines short chain PFCs (PFHxA, PFHpA and PFBS) in whole fish homogenates. PFHxA was found in the fish from all three rivers, with concentrations ranging from $<$ LOQ to $18.4 \mathrm{ng} / \mathrm{g}$ and a median of $3.71 \mathrm{ng} / \mathrm{g}$.

Total PFCs (a summation of the PFC concentrations measured in individual fish) ranged from less than the LOQ to a maximum of $1270 \mathrm{ng} / \mathrm{g}$, with the median individual sample having a total concentration of $53.4 \mathrm{ng} / \mathrm{g}$ PFCs. Median total PFC levels tended to be higher in the Mississippi River $(66.4 \mathrm{ng} / \mathrm{g}$ ) compared to the Ohio River (57.6 ng/g) and Missouri River (38.4 ng/g) but these differences were not statistically significant.

\subsection{Composition profiles of various PFCS}

PFOS was the predominant PFC contributing $86.3 \%$ of the total PFC in all rivers, with $72.9 \%$ from the Ohio River, $73.1 \%$ from the Missouri River, and 91.4\% from the Mississippi River (Supporting information, Fig. S1). While PFOS dominated the composition

Table 2

PFC concentrations (ng/g wet weight) by river

\begin{tabular}{|c|c|c|c|c|c|c|c|c|c|c|c|c|}
\hline \multirow[t]{2}{*}{ River } & \multirow[t]{2}{*}{ Statistics } & \multicolumn{10}{|l|}{ Analyte } & \multirow[t]{2}{*}{ Total $\mathrm{PFC}^{\mathrm{C}}$} \\
\hline & & PFOS & PFHxS & PFBS & PFDoA & PFUnA & PFDA & PFNA & PFOA & PFHpA & PFHxA & \\
\hline \multirow[t]{5}{*}{ MO } & $N>\mathrm{LOQ}^{\mathrm{a}}$ & 13 & 13 & 2 & 10 & 2 & 4 & 10 & 0 & 18 & 15 & 87 \\
\hline & Min & $<10.0$ & $<0.20$ & $<0.40$ & $<0.20$ & $<1.00$ & $<0.20$ & $<0.20$ & $<1.00$ & $<1.00$ & $<4.00$ & 5.90 \\
\hline & Mean $^{\mathrm{b}}$ & 84.7 & 1.89 & $<0.40$ & 0.49 & $<1.00$ & 0.25 & 0.43 & $<1.00$ & 1.53 & 5.15 & 95.2 \\
\hline & Median $^{\mathrm{b}}$ & 24.4 & 0.87 & $<0.40$ & $<0.20$ & $<1.00$ & $<0.20$ & $<0.20$ & $<1.00$ & 1.80 & 5.53 & 38.4 \\
\hline & Max & 532 & 8.14 & 0.64 & 2.88 & 8.60 & 2.0 & 1.48 & $<1.00$ & 4.03 & 12.6 & 536 \\
\hline \multirow[t]{5}{*}{ MS } & $N>\mathrm{LOQ}^{\mathrm{a}}$ & 20 & 10 & 1 & 5 & 5 & 18 & 11 & 5 & 3 & 14 & 92 \\
\hline & Min & 10.0 & $<0.20$ & $<0.20$ & $<0.40$ & $<0.40$ & $<0.40$ & $<0.20$ & $<0.20$ & $<0.20$ & $<2.00$ & 14.4 \\
\hline & Mean $^{\mathrm{b}}$ & 83.1 & 0.42 & $<0.20$ & $<0.40$ & 3.38 & 1.24 & 0.78 & $<0.20$ & 0.27 & 3.42 & 93.2 \\
\hline & Median $^{\text {b }}$ & 53.9 & 0.18 & $<0.20$ & $<0.40$ & $<0.40$ & 1.05 & 0.27 & $<0.20$ & $<0.20$ & 3.06 & 66.4 \\
\hline & Max & 250 & 3.33 & 0.29 & 1.25 & 48.0 & 5.16 & 5.38 & 0.60 & 1.83 & 11.1 & 286 \\
\hline \multirow[t]{5}{*}{$\mathrm{OH}$} & $N>\mathrm{LOQ}^{\mathrm{a}}$ & 16 & 12 & 0 & 15 & 17 & 17 & 14 & 1 & 0 & 8 & 100 \\
\hline & Min & $<10.0$ & $<0.20$ & $<0.40$ & $<1.00$ & $<0.40$ & $<1.00$ & $<0.20$ & $<1.00$ & $<4.00$ & $<10.0$ & 11.3 \\
\hline & Mean $^{\mathrm{b}}$ & 147 & 0.52 & $<0.40$ & 1.72 & 6.57 & 3.88 & 1.03 & $<1.00$ & $<4.00$ & $<10.0$ & 166 \\
\hline & Median $^{\mathrm{b}}$ & 31.8 & 0.48 & $<0.40$ & 1.87 & 4.52 & 4.10 & 0.42 & $<1.00$ & $<4.00$ & $<10.0$ & 57.6 \\
\hline & Max & 1250 & 1.96 & $<0.40$ & 4.13 & 45.3 & 9.01 & 5.89 & 2.10 & $<4.00$ & 18.4 & 1270 \\
\hline \multirow[t]{5}{*}{ Total } & $N>\mathrm{LOQ}^{\mathrm{a}}$ & 49 & 35 & 3 & 30 & 24 & 39 & 35 & 6 & 21 & 37 & 279 \\
\hline & Min & $<10.0$ & $<0.20$ & $<0.20$ & $<0.20$ & $<0.40$ & $<0.20$ & $<0.20$ & $<0.20$ & $<0.20$ & $<4.00$ & 5.90 \\
\hline & Mean $^{\mathrm{b}}$ & 105 & 0.94 & $<0.20$ & 0.84 & 3.50 & 1.79 & 0.74 & $<0.20$ & 0.64 & 4.67 & 118 \\
\hline & Median $^{\mathrm{b}}$ & 37.4 & 0.36 & $<0.20$ & $<0.20$ & $<0.40$ & 0.82 & 0.30 & $<0.20$ & $<0.20$ & 3.71 & 53.4 \\
\hline & Max & 1250 & 8.14 & 0.64 & 4.13 & 48.0 & 9.01 & 5.89 & 2.10 & 4.03 & 18.4 & 1270 \\
\hline
\end{tabular}

MO, Missouri River; MS, Mississippi River; OH, Ohio River. Twenty samples from each river.

${ }^{a}$ Number of fish samples with concentration above LOQ.

b For samples under LOQ half of LOQ was assigned to each compound for the calculation of mean and median.

c Total PFC assessed by individual fish, $n=20$ for each river. 
profiles for most individual sampling sites on each river, distinctive profiles were observed for each individual sample analyzed (Supporting information, Fig. S2). This may reflect differences in water quality and/or species specific uptake and elimination of the target compounds. In the Mississippi River, PFOS consistently contributed the most to total PFCs for all sampling sites. However, the profiles were much more variable on the Ohio and Missouri Rivers, suggesting less relative influence of PFOS or perhaps a greater variety of source inputs. Aside from PFOS, PFHxA was the most prevalent PFC contributing $16.6 \%$ of total in the Missouri River and $5.6 \%$ of in the Mississippi River. PFUnA and PFDA contributed 10.4 and $9.4 \%$, respectively, of total $\mathrm{PFC}$ in the Ohio River.

\section{Discussion}

In Table S3 the mean PFC concentrations from this study are compared to mean concentrations from a small number of previously reported studies that have also used whole fish homogenates for analysis. The results from studies conducted in the US Great Lakes region (Martin et al., 2004; Kannan et al., 2005; Furdui et al., 2007) were substantially similar to the present work, with PFOS accounting for the majority of the PFCs measured. The highest PFOS concentration in these studies $(450 \pm 98 \mathrm{ng} / \mathrm{g})$ was found in whole sculpin homogenate from Lake Ontario (Martin et al., 2004), approximately one-half the maximal value found in the present study for threadfin shad from the Ohio River (1250 ng/ g). Taken together, these studies provide evidence that PFC contamination in freshwater fish is widespread in portions of the central and eastern US.

Most of the other studies performed to date have measured PFC concentrations in the liver and blood (Taniyasu et al., 2003; Houde et al., 2006), making comparisons to the current study difficult. Liver and blood are the tissues where PFCs have been shown to accumulate, but because humans most often only eat fish fillets, the concentrations in muscle tissue are clearly the most important measurement for assessing potential human exposures. Because the relationship between fish body compartments remain unknown at this time, it is extremely difficult to compare and interpret the results from all of the existing studies. It also makes it difficult to make meaningful generalizations about geographical distributions and the interrelationships between various species. A study which examines the species-specific body disposition of the PFCs, comparing blood, liver, muscle, and whole body homogenate, would help to establish these relationships and make all of the data that have been published more useful.

These compounds are not known to be degraded or transformed in biological systems or the environment and transport between these widely separated drainage basins is unlikely. Considering the widespread occurrence and variable ranges of the PFCs documented in this study, it seems likely that there are many different sources of the PFCs present on these large North American rivers. The limited amount of work that has been done on this subject suggests that point source effluents may be responsible for locally elevated PFC concentrations found in some fish species. For example, in a report from Minnesota (Oliaei et al., 2006), elevated PFC levels were detected in wastewater, river water, sediment, and fish from the Mississippi River area near a chemical manufacturing facility in the Minneapolis-St. Paul area. The scattered nature of the high levels determined in the current study is consistent with this hypothesis, but much further work in this area must be completed to examine this fully.

Among the large fish listed in Table S2, the median PFOS concentration was significantly higher in piscivorous fish $(88.0 \mathrm{ng} / \mathrm{g})$ when compared to the non-piscivorous species $(15.9 \mathrm{ng} / \mathrm{g}$, $p=0.01$ ). This observation is consistent with previous studies which also demonstrate higher levels of PFCs in top predator species in aquatic food chains (Martin et al., 2004; Kannan et al., 2005). It is also interesting to examine the differences between pelagic and benthic feeders. For example, the median PFOS level in shad (primarily benthic feeders) was $232 \mathrm{ng} / \mathrm{g}$, which is almost nine times higher than the pelagic feeding shiner at $26.5 \mathrm{ng} / \mathrm{g}(p=0.08)$. While this result only approaches significance in this analysis, it is consistent with a previous study which noted elevated PFC levels in benthic fauna (Martin et al., 2004). While these ecological observations are clearly tentative, being based on only a small number of observations in this study, they illustrate how application of a whole fish homogenate method is useful in evaluating trophic level dynamics and interspecies relationships.

At least one study has suggested that consumption of PFCcontaminated fish may be related to PFC levels in human blood (Falandysz et al., 2006). In recognition of the potential for human exposures via this route, the Minnesota Department of Health has recently issued fish consumption advisories for contaminated sections of the Mississippi River (Minnesota Department of Health, 2007b). This advisory suggests that people limit their intake of fish to no more than one meal a week if PFOS levels in fillets exceed $38 \mathrm{ng} / \mathrm{g}$. It is therefore interesting to note that $48 \%$ of the whole fish homogenates examined in this study had PFOS levels that exceeded that threshold. As noted above, the relationship between measurements made with homogenates and fillets has not been examined, but the proportion of samples from this study that exceeded this advisory limit indicates that consumption of fish from this region may be a route of PFC exposure that needs further evaluation. A recent survey of people living in the eight US states that boarder the Great Lakes found that $84 \%$ included fish (from any source) in their diet, with the consumption of sport-caught fish being highest in Minnesota (44\%) and Wisconsin (39\%) (Imm et al., 2005). The same survey estimated that 2.9 million people in the Great Lakes region had more than 104 fish meals per year from all sources (commercial and sport-caught).

\section{Conclusion}

In summary, a method to measure PFCs in whole fish homogenate using alkaline digestion and solid phase extraction followed by LC/MS/MS analysis has been developed and tested. The performance characteristics described above demonstrate that this method is accurate, precise, and useful in studies intended to evaluate the distribution of PFCs in fish populations. This method was successfully applied to material collected as part of the USEPA's EMAP GRE study and provides evidence of the widespread presence of the PFCs in fish from the three largest rivers in the east central US. It is clear that a great deal of work remains to be done to adequately describe the distribution of these materials in aquatic ecosystems and to estimate potential human exposures resulting from the consumption of fish from this region.

\section{Acknowledgments}

This research was supported in part by an appointment to the Research Participation Program at the National Exposure Research Laboratory administered by the Oak Ridge Institute for Science and Education (ORISE) through an interagency agreement between the US Department of Energy and the US Environmental Protection Agency. We thank Cameron Ross, Catherine Clark, Sarah Schaefer and Melissa Keckeis of the Dynamac Corporation, c/o US EPA NERL Cincinnati, for the initial fish tissue homogenization and aliquot preparation for this study. Support from Waters Corporation through Cooperative Research and Development Agreement (\# 392-06) is gratefully acknowledged. The United States Environmental Protection Agency through its Office of Research and Development funded and managed the research described here. It has 
been subjected to agency review and approved for publication. Mention of trade names or commercial products does not constitute endorsement or recommendation for use.

\section{Appendix A. Supplementary data}

Supplementary data can be found, in the online version, at doi: 10.1016/j.envpol.2008.03.014.

\section{References}

Boulanger, B., Vargo, J., Schnoor, J.L., Hornbuckle, K.C., 2004. Detection of perfluorooctane surfactants in Great Lakes water. Environ. Sci. Technol. 38, 40644070.

Falandysz, J., Taniyasu, S., Gulkowska, A., Yamashita, N., Schulte-Oehlmann, U., 2006. Is fish a major source of fluorinated surfactants and repellents in humans living on the Baltic Coast? Environ. Sci. Technol. 40, 748-751.

Furdui, V.I., Stock, N.L., Ellis, D.A., Butt, C.M., Whittle, D.M., Crozier, P.W., Reiner, E.J., Muir, D.C., Mabury, S.A., 2007. Spatial distribution of perfluoroalkyl contaminants in lake trout from the Great Lakes. Environ. Sci. Technol. 41, 1554-1559.

Giesy, J.P., Kannan, K., 2001. Global distribution of perfluorooctane sulfonate in wildlife. Environ. Sci. Technol. 35, 1339-1342.

Hansen, K.J., Clemen, L.A., Ellefson, M.E., Johnson, H.O., 2001. Compound-specific, quantitative characterization of organic fluorochemicals in biological matrices. Environ. Sci. Technol. 35, 766-770.

Hansen, K.J., Johnson, H.O., Eldridge, J.S., Butenhoff, J.L., Dick, L.A., 2002. Quantitative characterization of trace levels of PFOS and PFOA in the Tennessee River. Environ. Sci. Technol. 36, 1681-1685.

Houde, M., Martin, J., Letcher, R.J., Solomon, K., Muir, D.G., 2006. Biological monitoring of polyfluoroalkyl substances: a review. Environ. Sci. Technol. 40, 34643474.

Imm, P., Knobeloch, L., Anderson, H.A., The Great Lakes Sport Fish Consortium, 2005. Fish consumption and advisory awareness in the Great Lakes basin. Environ. Health Perspect. 113, 1325-1329.

Kannan, K., Tao, L., Sinclair, E., Pastva, S.D., Jude, D.J., Giesy, J.P., 2005. Perfluorinated compounds in aquatic organisms at various trophic levels in a Great Lakes food chain. Arch. Environ. Contam. Toxicol. 48, 559-566.

Kennedy, G.L., Butenhoff, J.L., Olsen, G.W., O’Connor, J.C., Seacat, A.M., Perkins, R.G., Biegel, L.B., Murphy, S.R., Farrar, D.G., 2004. The toxicology of perfluorooctanoate. Crit. Rev. Toxicol. 34, 351-384.

Kudo, N., Kawashima, Y., 2003. Toxicity and toxicokinetics of perfluorooctanoic acid in humans and animals. J. Toxicol. Sci. 28, 49-57.

Martin, J.W., Whittle, D.M., Muir, D.C., Mabury, S.A., 2004. Perfluoroalkyl contaminants in a food web from Lake Ontario. Environ. Sci. Technol. 38, 5379-5385.
Minnesota Department of Health, 2007a. Hazardous Substances in Minnesota Perfluorochemicals in Minnesota. http://www.health.state.mn.us/divs/eh/ hazardous/topics/pfcs/.

Minnesota Department of Health, 2007b. Fish Consumption Advisory Program. Meal Advice Categories Based on Levels of PFOS in Fish. http://www.health. state.mn.us/divs/eh/fish/eating/mealadvicetable4.pdf.

Nakayama, S., Strynar, M.J., Helfant, L., Egeghy, P., Ye, X., Lindstrom, A.B., 2007 Perfluorinated compounds in the Cape Fear Drainage Basin in North Carolina. Environ. Sci. Technol. 41, 5271-5276.

Oliaei, F., Kriens, D., Kessler, K., 2006. Investigation of Perfluorochemical (PFC) Contamination in Minnesota Phase One. http://www.peer.org/docs/mn/06_27_ 2_pfc_report.pdf.

Organisation for Economic Co-operation and Development, 2002. Hazard Assessment of Perfluorooctane Sulfonate (PFOS) and its Salts. Organisation for Economic Co-operation and Development, Paris, France.

Prevedouros, K., Cousins, I.T., Buck, R.C., Korzeniowski, S.H., 2006. Sources, fate and transport of perfluorocarboxylates. Environ. Sci. Technol. 40, 32-44.

Seacat, A.M., Thomford, P.J., Hansen, K.J., Clemen, L.A., Eldridge, S.R., Elcombe, C.R. Butenhoff, J.L., 2003. Sub-chronic dietary toxicity of potassium perfluorooctanesulfonate in rats. Toxicology 183, 117-131.

State of New Jersey Department of Environmental Protection, 2007. Guidance for PFOA in Drinking Water at Pennsgrove Water Supply Company. http://www. state.nj.us/dep/watersupply/pfoa_dwguidance.pdf.

Taniyasu, S., Kannan, K., Horii, Y., Hanari, N., Yamashita, N., 2003. A survey of perfluorooctane sulfonate and related perfluorinated organic compounds in water, fish, birds, and humans from Japan. Environ. Sci. Technol. 37, 2634-2639.

Taniyasu, S., Kannan, K., So, M.K., Gulkowska, A., Sinclair, E., Okazawa, T., Yamashita, N., 2005. Analysis of fluorotelomer alcohols, fluorotelomer acids, and short- and long-chain perfluorinated acids in water and biota. J. Chromatogr. A 1093, 89-97.

US EPA, 2002. Revised Draft, Hazard Assessment of Perfluorooctanoic Acid and its Salts. US Environmental Protection Agency, Washington, DC.

US EPA, 2006a. 2010/15 PFOA Stewardship Program. Us Epa, Washington, DC. http:// www.epa.gov/oppt/pfoa/pubs/pfoastewardship.htm.

US EPA, 2006b. Environmental Monitoring and Assessment Program: Great River Ecosystems, Field Operations Manual. EPA/620/R-06/002. http://www.epa.gov/ emap/greatriver/fom.html.

van Leeuwen, S.P., Kärrman, A., van Bavel, B., de Boer, J., Lindström, G., 2006 Struggle for quality in determination of perfluorinated contaminants in environmental and human samples. Environ. Sci. Technol. 40, 7854-7860.

Weisbrod, A.V., Burkhard, L.P., Arnot, J., Mekenyan, O., Howard, P.H., Russom, C. Boethling, R., Sakuratani, Y., Traas, T., Bridges, T., Lutz, C., Bonnell, M. Woodburn, K., Thomas, P., 2007. Workgroup report: review of fish bioaccumulation databases used to identify persistent, bioaccumulative, toxic substances. Environ. Health Perspect. 115, 255-261.

Yamashita, N., Kannan, K., Taniyasu, S., Horii, Y., Petrick, G., Gamo, T., 2005. A global survey of perfluorinated acids in oceans. Mar. Pollut. Bull. 51, 658-668. 